\title{
Chemical Biodiversity and its Industrial Applicability
}

Biodiversity - the huge variety of living forms that makes up our biosphere - is a concept introduced in the scientific world by the Nature explorers in the last 400 years. As there was no formal division among areas of knowledge, scientists of the time had a comprehensive education in natural sciences, which encompassed physics, chemistry and medicine. Frequently their contributions had to do with several knowledge areas. In the 20th century, with knowledge being segmented into disciplines, the word "biodiversity" lost its importance until the defenders of the Environment, in a memorable campaign, succeeded in turning the biological diversity cause into a worldwide objective in itself, embodied in the $\mathrm{CBD}^{1}$ - the 1992 Convention on Biological Diversity, also known as Rio-92.

Rio-92 focus on the fact that, generally speaking, the world is divided into developed countries that have been successful in exploiting nature to generate their wealth and the others that have not. Differently from the ordinary division between economically rich and poor, the CBD recognizes a sort of division between rich and poor concerning natural biological resources. A careful reading of the text makes it clear that its goal is not "saving the nature", but establishing the trade conditions in which conservationist concepts are expected to match with the continuing access of the productive sector - both national and international - to what can be and should be taken from the biosphere, but in a sustainable way.

Thus, the CDB provides for industrial development by those capable of achieving it in accordance with the proposed principles of biological and environmental sustainability. Scientific modernism immediately makes us conclude that most actions will be centered on the exploration of the genetic potential in biodiversity. We should agree with it, but in the long run. It is fundamental to realize that biodiversity can provide for different industrial uses not yet connected - or not connected only - with DNA chemistry. Logging, considered an anathema by many, will proceed vigorously and legally as long as wood remains a valuable industrial input. The same will happen with the forest fruits and medicines, no matter if it they are natural or cultivated. It is worth noting that the great driving force of Rio-92 has been the interest of the chemical-pharmaceutical industry of the industrial countries, which fought for unrestricted access to chemical natural resources. The Rio-92 Convention stipulates that each country's biodiversity becomes a national asset, giving each country the right to decide the trade conditions with the other Convention state members. Such concept has formally broken with the previous understanding that the natural bioresources belonged to everyone and so could be disposed of anywhere in the World by local or foreign enterprise. The same conceptual rupture is true even concerning the biodiversity scientific study. ${ }^{2}$

Twenty years after Rio-92, it is now clear how extremely unequal were the countries holding most of the global biodiversity - the megadiverse countries - in their capability to manage their natural resources and to take advantage of them for the purpose of advancement, not only economically, but also technologically and scientifically. The first attempts to legislate and regulate the biodiversity uses in Brazil came with Senator Marina Silva's Law Project 306/1995 presented before the Brazilian Senate. Such bill is still being discussed, but, in 2000, the disastrous NOVARTIS BIOAMAZONIA affair caused the Government to issue a regulatory interim measure, the initial text of which was also disastrous for everybody's access to the Brazilian biodiversity, the Brazilian scientific community included. The 2186/2001 Interim Measure, in its present and more flexible format, is in force till this day. As years passed by, it has been improved by several decrees, because only the promulgation of a final regulatory Law by Congress can replace it. This super-law on the access to the Brazilian diversity is still in the waiting room of the Presidency, awaiting final discussion and proposal to Congress. All taken into consideration, Brazilian regulation for Access to Biodiversity is among the best and most comprehensive among megadiverse countries. Less developed megadiverse countries are still striving for better trade conditions that will effectively result in technology and scientific transfer alongside economic advantage beyond the benefit of this or that central power holder.

Nowadays, biodiversity is appropriately seen in Brazil as one of the most important sources for the nation's empowerment. Thus, we should focus on devising sustainable and conservative ways to permit the Brazilian productive sector, that is, all the companies legally established in Brazil, to access this resource. Leaving aside the less sophisticated uses of biodiversity, it is obvious that there is room for the development of the chemistry of biodiversity as well as for strengthening our still fledgling biotechnology of biodiversity. These application areas require a better knowledge of our biodiversity, not only from the botanic and eco-systemic point of view, but also from the chemical one. So, it is necessary to systematize collection procedures, followed by chemical processing of Field samples in order to implement large-scale chemical biodiversity collections and databases, available for research and industrial bioprospection. Such databases should be closely linked with lab systems equipped for the extraction and the refined chemical study of the stored materials. It will also be fundamental to provide such labs with high throughput screening systems capable of quickly identifying substances of interest through assays assembled to test desired properties, be it a biochemical reaction or a physical-chemical characteristic. Although there are in Brazil both public and private significant efforts to deal with the chemistry of biodiversity, cohesion of forces around the sort of goals mentioned above is still lacking. It will be essential to develop an open model, able to match reciprocal assistance under the understanding that knowledge should lead to the economic activity. We will need to bring together knowledge, people and high-level resources. I am afraid that only a very definite and energetic biodiversity policy will succeed in harnessing Brazilian Biodiversity and bringing it to fruition, for the benefit of scientists, entrepreneurs and the Brazilian Society as a whole.

Antonio Paes de Carvalho EXTRACTA Moléculas Naturais S/A CEO

\section{References}

1. http://www.cbd.int/, acessed in February 2011.

2. http://www.mma.gov.br/index.php?ido=conteudo. monta\&idEstrutura=85, acessed in February 2011. 